\title{
Using multimedia for vocabulary teaching
}

\author{
Nurmurodova Shakhnoza Ibragimovna ${ }^{1}$ \\ ${ }^{1}$ Bukhara State Engineering and Technological Institute, Uzbekistan
}

Email: nurmurodova sh@umail.uz

\begin{abstract}
In article was discussed importance of multimedia in teaching English and mainly English vocabulary. This article devotes to teaching vocabulary with the help of multimedia, its advantages and disadvantages to teaching English in EFL and ESP classes.
\end{abstract}

Keywords: multimedia, teaching, teaching English, learning environment, word, effectiveness, EFL,ESP.

\section{INTRODUCTION}

However, multimedia is not used only for glossing texts. Multimedia is a central component of good computer-assisted skill-building software. Thus, Chanier and Selva (1998) stressed the benefits of multimedia support for learning L2/FL vocabulary and presented ALEXIA, a lexical learning environment for French as a L2/FL, which includes a corpus of texts, a general and a personal dictionary, and a lexical activities unit. After reviewing various viewpoints about the effectiveness of multimedia for vocabulary learning, they propose useful criteria for evaluating the quality of a visual representation in a lexical environment. Groot (2000) presented another multimedia-enhanced computer-assisted word acquisition program, called CAVOCA, whose aim was to speed up the vocabulary acquisition process. CAVOCA is an interactive program that takes learners through different stages of vocabulary development: deduction, consolidation, and long-term retention.

Similarly, Tozcu and Coady (2004) conducted a case study that examined the outcomes in vocabulary acquisition when using interactive computer-based texts as opposed to traditional materials. The aim was to determine the effect of direct vocabulary instruction via computer assisted learning as opposed to traditional vocabulary training via print texts. Moreover, the effect of this direct instruction on reading comprehension and word recognition speed and therefore reading rate were also analyzed. The subjects of the study were 56 intermediate level students from various L1 backgrounds who were studying English for university academic preparation. The results suggested that the treatment group, who used a tutorial computer assisted courseware, outperformed the control group in all the three analyzed areas: vocabulary knowledge, reading comprehension, and reading speed. These results suggest positive implications of integrating technology in the language classroom for reading instruction and vocabulary development.

\section{Benefits of Multimedia-enhanced Dictionaries}

Other research that focused on vocabulary development with technology argued for the increased effectiveness of multimedia-enhanced electronic dictionaries designed specifically for English language learners, and which have several built-in aids that their book counterparts cannot provide (e.g. the Longman Interactive English Dictionary, the Oxford Picture Dictionary Interactive, etc.) (Butler-Pascoe and Wiburg, 2003: 126-127).

Vocabulary-development Software without Multimedia Components

However, not all software for vocabulary development has a multimedia component, and a good example is concordance software, which triggers good results, since it allows for the examination of lexical, syntactic, and semantic patterns in various reading passages and contexts (Anderson, 1999: 32). This type of computer program can be a valuable instructional tool to raises students' awareness of the various types of lexical items in authentic contexts and provides non-threatening classroom experiences giving students opportunities to improve reading and vocabulary skills (Butler-Pascoe and Wiburg, 2003: 128). Benefits of Multimedia for Reading Comprehension 


\section{ANALYSES}

Multimedia is a great instructional component not only for vocabulary instruction, but also for reading comprehension, as some of the research presented above has suggested. The positive effect that multimedia has on reading comprehension comes, according to Busch (2003: 278), from the great advantage that online readers have over traditional printed readers: the possibility to enhance computerized texts with glosses in multimedia format. This is probably the reason why most studies dedicated to a computer-based approach to reading have focused on the usefulness of glosses in different formats to increase reading comprehension and vocabulary retention. Several researchers have argued for the positive effects that hypermedia has for L2/FL readers, because a text can be made more comprehensible for them by annotating it with multiple types of media glosses (Sakar and Ercetin, 2004: 28).

The effects of multimedia glossing received increased attention as researchers considered the possibility that computer-aided reading could create more proficient readers by offering a choice of various types of glosses to develop better vocabularies, greater background knowledge surrounding the text, and more effective reading strategies (Lyman-Hager and Davis, 1996: 775). Various studies argued that multimedia glossing is beneficial for reading comprehension and, consequently, for L2/FL vocabulary acquisition. Thus, Lomicka (1997) explored how multimedia annotations influenced the level of FL reading comprehension for students enrolled in a second semester French course. Three conditions were used when students were reading a text on the computer screen: full glossing, limited glossing, or no glossing. The results indicated that the students who had access to full glossing improved better than those who had access to either limited glossing or no glossing. Sakar and Ercetin (2004), who went even further and explored 44 adult intermediate-level EFL learners' preferences for hypermedia annotations, also suggested similar results. The results suggested that students preferred visual annotations to textual and audio annotations. Video and graphic annotations were accessed when students wanted to retrieve background information about the topic, and graphic annotations were used to illustrate the meanings of words.

\section{CONCLUSION}

In summary, it can be pointed out that vocabulary and reading comprehension are closely related, as it may be seen from the case studies presented above nearly all studies focused both on vocabulary and reading proficiency as they are influenced by multimedia. Vocabulary plays an important part in reading comprehension and techniques that are useful for vocabulary development (such as multimedia glossing) also benefit reading comprehension, and vice versa.

\section{REFERENCES}

1. Anderson, N. (1999) Exploring Second Language Reading. Issues and Strategies. Boston: Heinle \&Heinle Publishers.

2. Busch, H.-J. (2003) Computer Based Readers for Intermediate Foreign-Language Students. Educational Media International, 40 (3-4), pp. 277-185.

3. Butler-Pascoe, M. E. and K. M. Wiburg. (2003) Technology and Teaching English Language Learners. Pearson Education, Inc. pp. 114-137.

4. Brett, A \& Rothlein, L. (1996). Vocabulary acquisition from listening to stories and explanations of target Words. The Elementary School Journal, (96) 4,67-85.

5. Balochowicz, C. \& Fisher, P. (2000). Teaching Vocabulary. Manhwah, NJ: Erlbaum Brown, T. S. \& Perry, F. L. (1991). A comparison for three languagestrategies for ESL vocabulary acquisition. TESOL Quarterly, (25).4, 655-670

6. Chun, D.M. (1996). Effects of multimedia annotations on vocabulary acquisition. The Modern Language Journal, (80)2, 65-80.

7. Doff, A. (1989). An Introduction to English Language Teaching. Cambridge University Press. New York.

8. Egbert, J. (2005) CALL Essentials. Principles and Practice in CALL Classrooms. TESOL, Inc.

9. Groot, P. (2000) Computer Assisted Second Language Vocabulary Acquisition. Language Learning \&Technology, 4 (1), pp. 60-81. 